\title{
The Internet of Things: Enabling Opportunities and Challenges
}

\author{
James A. Cunningham and Jason Whalley
}

\begin{abstract}
There is much market hype about the potential of IoT to transform firms and industries. Taking perspective of actors in the quadruple helix-industry, government, universities and end users-we consider the enabling opportunities and challenges that IoT brings. Enabling opportunities for firms include firm purpose reconfiguration, competitive disruption and market dominance, value reconfiguration, value creation and business models environmental and customer insights and ecosystem integration. Regulation, infrastructural investment and capacity, societal awareness and adoption, entrepreneurial ecosystem development are challenges that IoT brings to quadruple helix actors. The chapter concludes by discussing the implications of IoT for these actors.
\end{abstract}

J. A. Cunningham $(\bowtie) \cdot J$. Whalley

Newcastle Business School, Northumbria University, Newcastle upon Tyne, UK e-mail: james.cunningham@northumbria.ac.uk

J. Whalley

e-mail: jason.whalley@northumbria.ac.uk

(C) The Author(s) 2020

J. A. Cunningham and J. Whalley (eds.), The Internet of Things Entrepreneurial Ecosystems, https://doi.org/10.1007/978-3-030-47364-8_7 
Keywords Entrepreneurial ecosystems · Quadruple helix · Challenges · Opportunities · Internet of Things

\subsection{INTRODUCTION}

The preceding chapters provide some insights into different aspects surrounding the IoTs. On the one hand IoT provides significant opportunities for established firms, nascent entrepreneurs and ultimately customers. On the other hand, IoT challenges conventional norms with respect to privacy, security, competition and regulation. IoT has the capacity to substantially reconfigure established innovation ecosystems that recreates value in unimagined ways that have global reach and significance. It creates new tensions within firms as to how they respond to the opportunities IoT offers to enhance or reconfigure their competitive position. Should firms make the decision to fully embrace IoT in all aspects of their activities and open up new collaborative opportunities, as well as new mechanisms to generate and sustain value creation? Or do firms take a more adaptive approach so as to better understand the potential and constraints that IoT could place on their competitive positioning? Alternatively, firms may simply ignore IoT altogether and not be persuaded and or tempted to act by the market hype that surrounds IoT. These are some of the strategic question facing firms as they consider the enabling opportunities and challenges of IoT adoption. Those firms investing and advancing their IoT capacity are pioneering different means through which they can persuade end users of the value they have created for them by integrating and embedding IoT capacity into their value propositions. Such firms are also challenging and changing established industry and competitive norms through competitive disruption enable by IoT.

For national governments IoT brings forth a plethora of policy challenges that requires urgent policy analysis and attention given the significant growth of IoT across industrial sectors. IoT has the potential impact on many aspects of the lived experiences of citizens. Given the growing intense scientific and technological competition between countries governments cannot afford to ignore the economic benefits of IoT. However, the policy challenges posed by IoT pervade the economy and society and these challenges centre on such issues as regulating competition, consumer rights, individual citizen human and privacy 
rights, telecommunications and information technology (IT) infrastructure investment and public sector entrepreneurship programmes that support entrepreneurial ecosystem building to support IoT firms. For example, how should governments support nascent entrepreneurship, prioritise public research programmes and guard against widening region and socio-economic divides that result from the pervasive national IoT adoption across the private and public sectors.

IoT is a growing multidisciplinary domain. For universities and public research organisations how do they support research communities to make the research advances necessary that underpin much of the hyped market potential of IoT? How do universities collaborate with other quadruple helix actors to support IoT entrepreneurial ecosystems? End users in the form of consumer will ultimately through the decision to purchase or not determine the fate of firm level IoT adoption. However, collectively ends users are becoming increasingly aware of their rights. Beyond the early adopters, the diffusion of IoT related products and services may be more challenging given the growing societal awareness and general apprehension they have in relation to issues such as privacy, data management etc.

Against the background the purpose of this chapter is to examine some of these enabling opportunities and challenges that IoT presents and consider the implications this has in relation to economic development and societal advancement. We conclude the chapter by considering these implications through the prism of the quadruple helix actors-government, industry, academia and end users.

\subsection{ENABLING OpPortunities}

A core theme that has emerged throughout the chapters is the potential that IoT has to offer firms, industries and society. Rather than focusing on where are the IoT market and industry opportunities, akin to technology forecasting, which is not our focus we consider the enabling opportunities that IoT can offer mainly from a firm perspective. In particular we see the enabling opportunities as firm purpose reconfiguration, competitive disruption and market dominance, value reconfiguration, value creation and business models environmental and customer insights and ecosystem integration. 


\section{Firm Purpose Reconfiguration}

Since the 2008 global economic crash and subsequent recovery, the growth of high technology unicorn firms some of which have challenged if not transformed end user experiences, industry norms and challenged regulatory frameworks has brought into sharper focus the firm's interpretation and statement of purpose. In strategy terms, purpose centres on the who you are question? Many of the established industry and cross industry norms and assumptions have been challenged and contested as firms seek new market opportunities that have been unearthed by these events. The adoption of IoT has the potential to transform a firm's selfidentity and established purpose. In different sectors we are seeing firms slowly reconfiguring their stated purpose and how they define themselves. For example, Vodafone has reconfigured its purpose focused on telecommunications to having an entertainment and services purpose. Such a reconfiguration of purpose is being driven by anticipating changes in the external environmental factors, customer needs and also by the desire of these firms to carve out competitive positions that create uncontested markets or what is termed a 'blue ocean' that with a reconfigured purpose. Embracing IoT provides an enabling capacity to refine and reconfigure firm purpose. In doing so, firms are not conceiving their industrial and competitive environment through traditional approaches and norms. Considering the potential of IoT from an industry and firm perspective this can trigger firm level reflection as to their own purpose and their competitive sustainability over the medium to long term.

\section{Competitive Disruption and Market Dominance}

The evolution of IoT as outlined and discussed in Chapters 2 and 3 further affirms the real potential that IoT has to blur very distinctive industry boundaries that have been in place for decades. IoT provides a capability to incumbent firms to change the competitive dynamics within their competitive environment through competitive disruption. This might mean using IoT to collaborate with a variety of industry sector actors in their own or other industry sectors to form collaborative and network organisational arrangements designed to disrupt existing industries. In creating this disruption such firms can impose and create new means of competitive dominance that makes it difficult if not impossible for competitors to imitate or replicate. Moreover, IoT can be utilised by 
firms that do not have market dominance to create one in an accelerated manner, thereby forcing incumbent firms to scramble to hold onto their existing market dominance. Through competitive disruption IoT can reshape who is the strategic customer(s) either in a business-to-business (B2B) or business-to-consumer (B2C) context and can create different beach head markets to secure market dominance in an effective manner as possible. In essence, IoT can facilitate the opening up of new market opportunities that firms would not be able to pursue effectively in other industry sectors or in a manner that they can effectively and sustainability collaborate with a variety of stakeholders.

\section{Value Reconfiguration, Value Creation and Business Models}

IoT provides an enabling opportunity for firms to reconfigure tangible and intangible value for end users. Such a reconfiguration of value can create a more sustainable if not lifelong relationships with the end users that would frustrate if not undermine the efforts of competitors to persuade these ends users to switch. IoT can enable how value is built and leveraged into products and services that goes beyond just meeting an actual need but future needs that resonates and is credible with end users. Moreover, such a reconfiguration of value enables firms to reach a disruption tipping point in an accelerated fashion that competitors could find it challenging to emulate and keep pace with. Such a reconfiguration of value may be intentional and orientated towards industry level value destruction in order to create value that can be enabled by IoT. In terms of value creation, IoT should be viewed as an enabler to the reconfiguration of value rather than the sole central focus of the value creation.

IoT can support multi-sided market value creation in a sustainable and systematic manners that does not undermine the competitive positioning or efforts of a firm. IoT can provide opportunities for firms to deploy and or experiment with multiple business models. IoT combined with effective business model design can provide firms with valuable insights that enables further refinement of value. It also can enable a firm to pursue meaningful and sustainable collaborations with other firms in or outside their competitive environment or other stakeholders in building business models that are enable by IoT. Embracing IoT alongside effective business models can enable firms to transform their competitive position, long-term sustainability and economic attractiveness. Such as combination of effective business models and IoT can improve firm level cost efficiency 
and create a variety of profit pools at the firm level. In effect, it provides a firm with strategic posture that is sufficiently flexible to respond to unanticipated environmental pressures and end user needs.

\section{Environmental and End User Insights}

Within the chapters, various IoT examples have been cited that demonstrate its capabilities in different competitive and industry settings. Deployed effectively IoT can provide real insights into end user behaviours and the contextual use of a product and service. The real challenge for a firm is how best to use such rich sources of additional data and convert this into meaningful insights that can be used effectively for business model planning and reconfiguration or refinement of value. Firms need to plan how they integrate such data and additional insightsoften in real time-that enables them to respond to the changes due to immediate competitive pressures, as well as into new product or service development. Harnessed effectively such insights could provide early weak signs of environmental changes that a firm needs to take on board in their future planning particularly with respect to their horizon two, the medium to long-term view.

This capability that IoT can provide to firms can deepen the mastery of detail that firms need to have of their competitive environment that enables them to make the appropriate strategic and operational choices to maintain and grow their competitive position. In doing so, firms need to design effective analytical structures, processes and systems that are fit for purpose to generate meaningful insights into customer's personas across different industry and contextual settings. Investment in deploying IoT requires firms to have carefully thought through what raw data are they collecting from customers before, during and after product or service purchase and for customer use. Given that B2C customers are more becoming more aware of their data rights, firms need to carefully construct their IoT capability to overcome any natural concerns that individual end users may have with utilising their data to build customised end user insights.

\section{Ecosystem Integration}

Deployed effectively, with appropriate business model(s), the IoT can create the forces that result in stronger and closer ecosystem integration 
among stakeholders. Such ecosystem integration provides actors with the opportunity to create value through the combination of resources distributed among potentially many different actors, and to rapidly react to market opportunities through drawing on the resources and capabilities located in the ecosystem. Moreover, by drawing on the resources and capabilities of the ecosystem, firms are able to respond to a wider range of opportunities than would hitherto be the case if it acted alone.

Integration across the ecosystem may be driven by economic imperatives, with key stakeholders setting the agenda in terms of the technological standards adopted by actors as well as shaping the nature of the business model(s) adopted. Aside from firms, other actors may play a role in picking the IoT technologies or influencing the business model(s) that are adopted. Research institutes, supported by a combination of firms and (national) governments, could play a role in developing and then popularising key IoT technologies, enabling national standards to be adopted across an ecosystem that is likely to be international in scope. At the same time, governments, which are often large purchasers of IT as well as play a key role in sectors where IoT is likely to be significant, can facilitate the diffusion and adoption of IoT through supporting innovative business models in areas such as healthcare, logistics and so forth.

Challenges are, however, likely to emerge as ecosystem integration occurs. Ecosystems are composed of multitude actors, raising co-ordination challenges and costs on the one hand but also tensions as actors jostle for influence. One set of challenges is likely to be around the technological choices made by the ecosystem-the adoption of one IoT technology in preference to another will conference economic advantage(s) on those who control it. Another set of challenges is likely to emerge around the distribution of value across the ecosystem. Quite simply, will the allocation of value favour those who manufacture and assemble IoT technologies or will it be captured by those firms who assemble the products and services of others or those who interact with the end user?

Given the vast economic potential of IoT, there is also a geo-political dimension to the challenges emanating from ecosystem integration. National governments will, quite naturally, seek to position their countries so that it plays a key role in the IoT ecosystem, creating technologies, products and services that will be widely adopted by end-users. Through this positioning, one country will capture control of the ecosystem at the expense of others. Moreover, as governments establish IoT initiatives and 
support its development through, for example, investing in key sectors (health, education, transportation etc.) and amending their regulatory frameworks, attention will be drawn to the socio-economic context in which the firm operates. Differences in how intellectual property rights (IPR) and the privacy of end users are protected will influence the extent to which the integration of the ecosystem occurs, allowing actors based in some countries to play a more prominent and active role than those based elsewhere.

\subsection{Challenges}

The transformative potential of IoT has been well documented. Like any technological wave, the reality it comes with challenges for firms, government, third level institutions and end users/society. These challenges may directly impact on one quadruple helix actors and indirectly impact on the others. Some of these challenges can be overcome with appropriate and carefully considered interventions, particularly from government, in terms of policies, incentives and regulation. In particular the challenges we consider are regulation, infrastructural investment and capacity, societal awareness and adoption, and entrepreneurial ecosystem development.

\section{Regulation}

The significant growth of IoT and its deployment in different industrial and geographical settings provides challenges for regulators in multiple regulatory arenas. First, competition as IoT can provide firms with the rapid capacity to change the industry competitive setting through competitive disruption and securing market dominance. Much of the current regulatory framework has been developed around more traditional interpretations of competition. IoT challenges these interpretations and as such competition regulations and regulatory regimes have not kept pace with these changes. Moreover, as IoT provides the capability to quickly scale activities globally and across borders, this means firms can create competitive disruption and exploit more effectively regulatory environments that have not kept pace such competitive changes.

Second, IoT challenges traditional norms and understandings with respect to privacy and the use of data. Given recent changes within the European Union in relation to data handling and management via GDPR provisions and individual end users becoming more aware of the 
importance of protecting their own data, firms deploying IoT need to bear in mind how to balance individual end user privacy with the ability to collect and analysis data to provide the environmental and end user insights that informs future product or service development. Moreover, different countries have different regulations, case law and social norms in relation to individual privacy, data protection and handling. In utilising IoT firms need to plan how best to meet different legal and regulatory environments.

Third, as firms use IoT for $\mathrm{B} 2 \mathrm{C}$ markets there is a need to adhere to local consumer rights that individual end users have through a buyer seller transaction. In deploying IoT firms may use third party companies and different company holding structures as part of their competitive strategy. The challenge for individual end users is how they can assert their consumer rights under national law. This is also a challenge for regulators in how to ensure consumer rights where there may be multiple parties involved in fulfilling an end user purchase of a product or service. The challenge for firms is putting in pace effective structures and relationships that are acceptable to end users and reinforce value rather than destroy it.

Finally, worker rights and how IoT firms uphold these rights particularly as they can be using different contractual arrangements with individual employees across a variety of jurisdictions. Recent high-profile cases in relation to circular economy employment practices highlight the challenges facing firms. Firms need to balance having a flexible workforce capacity against having the appropriate contractual and employment practices that meet current and future anticipated needs. Undoubtedly, as IoT grows across the different industries settings the contractual practices and work practices used by companies will come to the fore and be challenged by unions and governments.

\section{Infrastructural Investment and Capacity}

Future scenarios that have been described that detail the transformative impact that IoT can have on business and society is dependent on the available infrastructure across different locations and geographical terrains. Across many developed countries there is a growing infrastructure divide between urban and rural locations and across socio-economic groups. There is also evidence across regions in developed countries that the quality of basic infrastructure is poor and substandard with regards to telecommunications services and internet access, thereby precluding 
citizens in these regions from accessing services or even digital government resources. The collective challenge that developed countries face is how to provide a high-level basic infrastructure that enables firms to deploy IoT capabilities that reaches end users seamlessly irrespective of geographical location. In developed economies this remains one of the greatest challenges and obstacles to the growth of IoT.

The challenge for governments is how to create an investment environment that will be attractive for private invest to support the development of such infrastructure beyond a minimum public services obligation on infrastructure operators. In environments such as developing economies where no such comparable infrastructure exists the challenges are even greater and the divides even wider. In a sense, the existing or non-existent infrastructure has the potential to slow, and in some contextual environments stop, firm IoT utilisation as it actually destroys the intended value that firms seek to provide end users.

\section{Societal Awareness and Adoption}

Like any new technological cycle there are always an ardent group of early adopters within firms and among end users. While some end users are willingness to explore or even adopt new IoT based products and services, the challenge is as the end user base grows they become more questioning of the implications it has for societal norms or how it can for example exacerbate societal inequality. Public and societal awareness in relation to embracing more digitalisation in daily living has increased due to news media stories such as Cambridge Analytica, public health studies of different age groups use of technology etc. Moreover, there is growing societal awareness in relation to individual privacy rights and how data is used by firms for their purposes and how personal data is also sold on to third party firms.

The challenge for government is to create regulatory environments that allow firms to fully embrace the potential of IoT, while also protecting long established personal rights that individual citizens have that are enshrined in law and built up in practice over decades. End users need to have the confidence that this balance pervades or else the willingness of individual citizens beyond early IoT technology adopters to emerge will be limited and from a firm perspective not commercially viable. 


\section{Entrepreneurial Ecosystem Development}

One of the challenges for governments is putting in place policies and mission orientated public research programmes that supports and encourages different actors to develop and grow entrepreneurial ecosystems that support IoT development. Does government support focus exclusively on the supply side or is in necessary to also focus on the demand side so end users are confident about procuring IoT related or based products and services? Given the pervasive nature of IoT, from a technology perspective a related challenge is research prioritisation for mission orientated research programme IoT investment. Does such research prioritisation take a sectoral approach and focus on areas of national strength or is it more cross-sectoral or just focused on a supply side constraint through the creation of IoT technology platforms? Moreover, careful consideration needs to be given to the configuration of research projects so that these projects have the maximum commercialisation impact for industry partners in their quest to secure dominant market positions.

Related to the project configuration challenge is what is the appropriate discipline mix that is required that both furthers original research and delivers research commercialisation. For nascent entrepreneurs the challenge lies in their ability to access other actors and resources within the entrepreneurial ecosystem that enables them to create new ventures that are scalable and survive the 'valley of death'. The challenge for policy makers is how best to support the entrepreneurial communities which are an essential and critical asset and resource in driving and delivering on IoT potential across different sectoral settings.

For universities and other third level institutions the ongoing challenges are in equipping graduates with the appropriate mix of knowledge, expertise and skills that they can flourish within IoT ecosystems irrespective of the contextual or environmental setting. In addition, their involvement through supporting researchers and research communities in pursuing IoT research and commercialisation is essential along with actively supporting faculty, graduate and student technology transfer that may result in patents and creation of spin-outs firms. Given the nature of IoT developments has the potential to change how universities and public research organisation organise their disciplines and the relevant professional support services. 


\subsection{IMPLICATIONS OF IOT Challenges and Opportunities}

The evolution of IoT as we have previously outlined brings enabling opportunities and challenges for firms, government and society. The transformative impact of IoT has the potential to be significant and systemic for business and society. We consider the implications of IoT enabling challenges and opportunities from the perspective of quadruple helix actors.

\section{Firms}

IoT has the potential for a firm to fundamentally rethink core aspects of its purpose, how it creates value and its business modelling. CEOs and top management within firms have to firstly decide the stance that they are going take with respect to IoT. Will they fully embrace IoT and all its potential or is a prudent approach is to see how IoT plays out in their competitive arena before making any decision to embrace IoT preferable? Such a decision is a challenging one given the fluidity of the perceived potential of IoT in different sectoral settings as opposed to the actual delivered enhanced performance enabled by IoT. Firms also have to consider the optimal mix of expertise and skills that they will need into order to embrace and leverage the benefits that IoT has to potentially offer their firm. This may mean creating new professional development programmes, changes in hiring policies and approaches or developing more collaborative relationships with external organisations so the firm has access to the skills and expertise that are necessary to exploit IoT. This may also mean changing the firm's whole innovation strategy and adopting more of an open innovation approach. Furthermore, given investment required to support developing firm level IoT capacity it will firms to change their techno-economic evaluation approaches. The complexity and decisions involved in such techno-economic evaluations for IoT that firms and other quadruple helix actors face was outlined in Chapter 4.

Moreover, IoT, like any new technological wave, has the potential to influence the cultural and social norms, management systems and processes. In other words, how employees are managed and how control systems are used that balances individual accountability against autonomy and creativity needs to be considered. The adoption of IoT has the potential to influence such balances as well as shape organisational and 
management structures. Firms need to work through these issues and plan accordingly if they are to exploit the potential of IoT to best affect. Finally, firms need to consider how they could use IoT to create a market dominant position. This may not be achieved pursuing obvious strategies and approaches already deployed in their competitive environment, but exploring other approaches in different contextual and environmental settings and across different ownership and organisation purposes-for profits, non-government organisations, co-operatives, public sector etc.

\section{Government}

Viewing IoT from an economic perspective for governments the potential impact it can have on a national economy can be substantial in terms of wealth creation, employment, taxation etc. IoT has the potential to support indigenous firms in their growth ambitions of becoming a born global or reaching unicorn status. For foreign direct investment (FDI) located firms that have embraced IoT it provides potential indirect and direct knowledge spillover effects for the regions they inhabit. It also can embed them further into a host country. However, to realise such economic potential governments need to take a proactive policy approach across different departments that is coherently designed to support IoT exploit across sectors and organization sizes irrespective of their geographical location. This means governments need to invest in developing their own expertise within public administration at national, regional and regional levels that is able to provide the best policy advice and support to realise IoT potential for firms and society as a whole.

As already mentioned, IoT also has to widen more inequalities between regions and among citizens. IoT is not bound by place in terms of creation and development on the supply side. However, on the demand side, the provision of infrastructure or access to IoT capabilities by firms, or by end users in terms of products or services, can be constrained by location and geographical peripherality. IoT provision and access can further widen the economic and social inequalities and further deepen existing digital, social and economic divides. Therefore, governments need to consider these issues in developing policy to support the growth of IoT to address, if not attempt to reverse such regional economic imbalances and social divides. Support government exploitation of IoT should not lead to greater levels of marginalisation or create new divides in society 
that undermines established individual constitutional rights as citizens of a nation.

While much of the contemporary examples of IoT applications are naturally centred on firms that have a for profit agenda, public sector services and organizations could potentially exploit IoT to enhance public service delivery or to support more effective public planning and administration. Moreover, deployed appropriately IoT can enable policy makers at national, regional and local level consistently consult, engage and even co-create with stakeholders and citizens on key policies.

\section{Universities and Public Research Organisations}

For universities and public research organisations IoT presents another arena that talented researchers and their communities can mobilise and utilise their knowledge, skills and expertise to support the supply side generation of IoT applications, infrastructure, etc. and, on the demand side, through research, policy and society engagement provide insights into how IoT adaption enhances or destroys economic and societal benefits. This requires universities and public sector organisations to have the entrepreneurial architecture within organisational structures that supports research commercialisation that is necessary for IoT exploitation, as well as research environments that supports research autonomy and respects research diversity. Moreover, such institutions need to encourage and organisationally support researchers who engage with other quadruple helix actors in the exploration and exploit of IoT on the supply or demand side. Beyond research, technology transfer and commercialisation universities can support the advance of IoT through undergraduate, postgraduate and customised/executive programmes that are design to meet the technical, operational and strategic dimension of exploiting IoT in a variety of organisational contexts.

\section{End Users}

Taking an end user perspective as a consumer IoT opens up new products and services that addresses unmet needs in areas such as health care, financial services, education etc. Potentially it may open up even greater consumer choice and enhanced personalisation of consumption based on individual tastes and preferences. However, end users need to be mindful of the individual trade-offs that IoT can have when it comes to issues such 
as privacy, data protection, individual rights etc. Such individual trade-off might be presented as benign by firms however the advancement of IoT further affirms the end users need to be fully informed before making any purchasing decision with respect to the immediate, medium to long term implications. End users need to mindful of the cost of ownership when they are making a purchase of IoT enabled products and services. IoT enabled devices may be priced attractively to entice end users but the cost of ownership over the lifetime of the product or service use might be very costly. End users might not be aware or fully informed as to the cost of ownership when they at the purchase stage. End users need to be aware of the full cost of ownership before making a purchase decision.

\subsection{CONCLUSIONS}

The purpose of the chapter, and the book more generally, was to reflect on some of the challenges and assumptions that are commonplace about the IoT. Without doubt IoT has the potential to be transformative in ways that have yet to be imagined. However, similar to any new technological wave it comes with challenges and implications that impact on society and potentially create some unintended consequences that are difficult, if not impossible, to reverse. From a societal perspective the overriding danger of IoT adoption is that it further widens existing societal and economic inequalities and divides rather than close them. Covid-19 has the potential to accelerate IoT that can transform business and society that address real societal needs. For IoT opportunities to be realized as a result of Covid-19 the challenges discussed in this chapter and through the various chapter contributions need to be addressed in a systematic manner by policy makers to ensure the maximum beneficial impact for society and business. 